\title{
Respostas da Universidade para a Integração Latino-Americana: o caso do PROLAM/USP ${ }^{1}$
}

\author{
Héctor Francisco Terenzi ${ }^{2}$ \\ Maria Cristina Cacciamali \\ Maria de Fátima José-Silva
}

\begin{abstract}
Resumo
O Programa de Pós-Graduação em Integração da América Latina da Universidade de São Paulo PROLAM/USP - foi constituído em 1988 com dois objetivos: responder às necessidades de aprofundar a produção de conhecimento dos processos de integração latino-americanos no campo das humanidades em suas diferentes dimensões: político, econômico, social, cultural e de relações internacionais; criar uma instância de reflexão acadêmico-científica para agregar e formar especialistas na temática, na qual a USP apresentava lacuna frente às universidades de excelência do exterior. A construção de um espaço institucional com essa finalidade foi motivada pela aceleração do processo de mudanças estruturais no fim da década de 80 , dos processos de mundialização e de integração regional, principalmente, dos países do Cone Sul. Este artigo apresenta inicialmente o contexto no qual este Programa de Pós-Graduação foi concebido e seus alvos primordiais. Na seqüência as seções foram estruturadas da seguinte maneira: na primeira seção expomos a concepção metodológica do PROLAM/USP, linhas de pesquisa e disciplinas oferecidas; na segunda analisamos as diretrizes de atuação, projetos desenvolvidos e as contribuições acadêmicas; na terceira seção evidenciamos os temas das dissertações de mestrado concernentes ao MERCOSUL; e na quarta seção ponderamos sobre o processo de auto avaliação do PROGRAMA e suas decorrências. Por fim, tecem-se as considerações finais.
\end{abstract}

Palavras-chave: Propostas da Universidade, Integração Latino-americana, PROLAM/USP.

\section{Resumen}

\footnotetext{
${ }^{1}$ A primeira versão deste trabalho foi apresentada no Seminário Internacional Mercosul, Presente e Futuro, pela Comissão de Cooperação Internacional da Universidade de São Paulo (CCInt/USP), Programa de PósGraduação em Integração da América Latina da Universidade de São Paulo (PROLAM/USP) e Programa de Lideranças para o Desenvolvimento Sustentável no MERCOSUL (PROLIDES) entre os dias 23 e 26 de maio de 2000, na Universidade de São Paulo, São Paulo, Brasil.

${ }^{2}$ Os autores são respectivamente: Professor Titular da Faculdade de Filosofia, Letras e Ciências Humanas da Universidade de São Paulo de Ribeirão Preto e Pró-Reitor de Pós-Graduação da Universidade de São Paulo no período 1997 a 2001, hecteren@usp.br; Professora Titular da Faculdade de Economia, Administração e Contabilidade da Universidade de São Paulo, atualmente Presidente da Comissão de Pós-Graduação do Programa de Pós-Graduação em Integração da América Latina da Universidade de São Paulo, e-mail: cciamali@uol.com.br; e Professora da Universidade Federal de São Paulo - Escola Paulista de Medicina, atualmente doutoranda do Programa de Pós-Graduação em Integração da América Latina da Universidade de São Paulo, e-mail: fatimajs@allnet.com.br. Os autores agradecem à Sra. Kátia Nobre secretária do PROLAM/USP pelo levantamento das informações.
} 
El Programa de Post- Graduación en Integración de América Latina de la Universidad de São Paulo PROLAM/USP- fue constituido en 1988 con dos objetivos: responder a la necesidad de profundizar en la producción de conocimiento de los procesos de integración latino-americanos en el campo de las relaciones humanas en sus diferentes dimensiones: político, económico, social, cultural y de las relaciones internacionales; crear una instancia de reflexión académico- científica para agregar y formar excelencia del exterior. La construcción de un espacio institucional con esa finalidad fue motivada por la aceleración de los procesos de cambios estructurales en el fin de la década de los 80, de los procesos de mundialización y de integración regional, principalmente, de los países de; Cono Sur. Este artículo se presenta inicialmente en el contexto en el cual este Programa de Post- Graduación fue concebido en sus metas primordiales. Consecuentemente, las secciones fueron estructuradas de la siguiente manera: en la primera sección exponemos la concepción metodológica del PROLAM/USP, líneas de investigación y disciplinas ofrecidas; en la segunda analizamos las directrices de actuación, proyectos desarrollados y las contribuciones académicas; en la tercera sección señalamos los temas de las disertaciones de maestría concernientes al MERCOSUL; y en la cuarta sección examinaremos los procesos de autoevaluación del PROGRAMA y sus decorrencias. Por fin, presentaremos las consideraciones finales.

Palabras-clave: Propuestas de la Universidad, Integración Latino-americana, PROLAM/USP.

\section{Introdução}

A Universidade Pública, no momento presente, enfrenta desafios constantes e prementes para superar os novos processos políticos, econômicos e sociais e suas necessidades decorrentes. A liberalização e a maior integração econômicas interagem com outras dimensões sociais, culturais, ideológicas e políticas e exigem respostas na produção do conhecimento, em sua tecnologia, organização e divulgação para refletir e intervir nessas novas realidades. Esse novo momento exige profissionais e especialistas com formação e perfil adequados para enfrentarem essa nova situação e contribuírem na criação de instituições gestadas nesse ambiente, fortalecendo a cidadania.

A mundialização altera o desenho e as práticas políticas, bem como as políticas econômicas dos governos na busca de uma reinserção internacional, que permita concretizar as aspirações de suas populações e legitimar seu poder político. A mídia é um instrumento poderoso para difundir ideologias e formar a opinião mundial sem fronteiras. A cultura e a arte criam e difundem padrões planetários acrescentando às especificidades nacionais e locais laços de integração entre os indivíduos e grupos sociais. Nesse contexto, o fortalecimento dos organismos multilaterais reconhecidos pelos governos, e os movimentos sociais internacionais tendem a tornarem-se mais efetivos para garantir uma 
ordem econômica mundial mais justa, estável, legítima e que garanta o desenvolvimento sustentável do planeta.

A concepção e a prática do trabalho, por outro lado, estão em transformação no momento contemporâneo. A sociedade assalariada modifica-se, em alguns países estreitase, e diferentes formas de organização para o trabalho convivem e articulam-se. Ganham relevo os pequenos empreendimentos, as cooperativas e as associações civis do terceiro setor. O eixo motor de absorção de mão-de-obra e geração de renda desloca-se do setor industrial e dos empregados registrados, com seguridade social, para o setor de serviços, espraiando-se por formas alternativas de categorias de trabalho: autônomo, terceirizado, e pequenos empreendedores formais e informais. Urge a necessidade do reconhecimento das novas demandas do trabalho inserido nesse contexto, a proposição e articulação de ações públicas que as contemplem, bem como a criação de instituições de seguridade social que as absorvam.

Estes fenômenos constituem um renovado campo de estudos e de formação de pessoas, especialmente para os países mais pobres, de tal forma a poderem contribuir para a construção de processos, programas e ações que lhes permitam usufruir os benefícios do progresso da humanidade. As universidades no Brasil, sobretudo públicas e dentre as quais com destaque a UNIVERSIDADE DE SÃO PAULO - USP, promovem uma de suas principais missões empenhando-se e efetivamente contribuindo com a mais ampla formação e desenvolvimento das pessoas para o trabalho e a cidadania. Renovam continuamente sua disposição em aprimorar um ambiente de debate e ação acerca do novo cenário, repensando e recriando suas atividades de ensino, pesquisa e extensão. Da mesma forma, reformatam os conhecimentos que acumulam para adequá-los convenientemente às novas e múltiplas demandas do complexo contexto do trabalho em sua forma interdisciplinar, multidisciplinar e quiçá transdisciplinar.

A UNIVERSIDADE DE SÃO PAULO -USP tem contribuído significativamente no sentido de formar e atualizar o conhecimento sobre e para o trabalho. Identificam-se diversas iniciativas que vêm sendo desenvolvidas e aplicadas por suas unidades, 
departamentos, órgãos, núcleos e fundações, conectadas com as transformações em curso e direcionados à finalidade de oferecer respostas concretas às demandas existentes, sob a configuração de apoios, serviços, assessorias, consultorias voltadas diretamente para aprimorar o desenvolvimento das pessoas. Mecanismos de controle e avaliação científica contribuem, por sua vez, para garantir a qualidade dos projetos. A formação em nível de graduação e de pós-graduação nas áreas tradicionais e em novas áreas que estão sendo criadas; o desenvolvimento do conhecimento através de programas de educação continuada e aberta e a informação através de diferentes formas de veículos são os pilares da atuação da Universidade na oferta de serviços, representando sua contribuição nos processos de renovação e ajustamento de nossa sociedade para os novos requerimentos do desenvolvimento das pessoas, do trabalho e da ação cidadã.

Constata-se como ilustração a partir de levantamento preliminar, utilizando-se como fonte o Banco de Especialistas da UNIVERSIDADE DE SÃO PAULO - USP, que mais de 170 especialistas da Universidade vinculados a 23 Faculdades ou Escolas envolvem-se com projetos e pesquisas relacionados com a formação e atualização de conhecimento para o trabalho, provenientes das unidades: Faculdade de Filosofia, Letras e Ciências Humanas; Faculdade de Medicina de Ribeirão Preto; Escola de Enfermagem de Ribeirão Preto; Escola de Comunicação e Artes; Escola de Engenharia de S. Carlos; Escola Politécnica; Escola Superior de Agricultura Luiz de Queiróz; Faculdade de Arquitetura e Urbanismo; Faculdade de Direito; Faculdade de Economia, Administração e Contabilidade; Faculdade de Economia, Administração e Contabilidade de Ribeirão Preto; Faculdade de Filosofia, Ciências e Letras de Ribeirão Preto; Faculdade de Odontologia; Faculdade de Odontologia de Bauru; Faculdade de Odontologia de Ribeirão Preto; Escola de Enfermagem; Escola de Educação Física e Esporte; Escola de Engenharia de São Carlos; Escola Politécnica; Faculdade de Ciências Farmacêuticas; Faculdade de Educação; Faculdade de Saúde Pública; Instituto de Ciências Biomédicas; Museu Paulista; Prefeitura do Campus de São Paulo; Prefeitura do Campus de Bauru; Reitoria. Destacam-se ainda relevantes projetos desenvolvidos pela CECAE - Coordenação de Cooperação Universitária e de Atividades 
Especiais; do Instituto de Estudos Avançados; Núcleos; Fundações (como Vanzolini, FIPE, FIA, FIPECAFI, da Medicina, entre outras); Empresas Juniores e Centros Acadêmicos.

A característica interdisciplinar e multidisciplinar da universidade, aliada aos conhecimentos acumulados e às diversas iniciativas praticadas pela UNIVERSIDADE DE SÃO PAULO - USP, corroboram para que seja dinamizado um ambiente capaz de promover a integração exigida por estas demandas, considerando de maneira integral às novas exigências do trabalho e da vida social.

\section{Programa de Integração da América Latina - PROLAM/USP}

O Programa de Pós-Graduação em Integração da América Latina - PROLAM/USP, criado em 1988 pela UNIVERSIDADE DE SÃO PAULO - e sua contribuição acadêmica efetivada por meio das pesquisas realizadas pelo seu Corpo Docente e das Dissertações de Mestrado defendidas sobre o tema da Integração Latino-Americana, constitui uma das respostas a esse novo contexto. Institucionalmente, o Programa foi estruturado como um espaço multidisciplinar interunidades objetivando estimular o diálogo e a cooperação entre os docentes, envolvidos setorialmente na USP e em outras universidade brasileiras e do exterior, pretendendo, igualmente, constituir-se como um foco para facilitar os contatos e intercâmbios entre instituições ou entidades pertinentes, no país e no exterior.

Assim, o primeiro objetivo do PROGRAMA, com caráter de agregação e formação de especialistas, constitui criar uma instância de reflexão acadêmico-científica (docência, pesquisa e extensão) sobre a temática latino-americana contemporânea, especialmente, sob a perspectiva da área de humanidades, na qual a USP apresenta lacuna frente às universidades de excelência do exterior. A construção de um espaço institucional com essa finalidade foi motivada pela aceleração do processo de mudanças estruturais no fim da década de 1980, dos processos de mundialização e de integração regional, principalmente, dos países do Cone Sul, e pelo maior aprofundamento dessas tendências relacionadas às relações comerciais, culturais, de idéias e de interatividade. 
O segundo objetivo, com caráter científico e metodológico, é a concepção de um processo multidisciplinar para apreender e compreender a realidade latino-americana em seus diferentes aspectos na construção do conhecimento nas Humanidades. A proposta central do PROGRAMA é o desenvolvimento de estudos sobre a América Latina, mediante estratégias comparativas de análise e reflexão crítica que permitam a produção do conhecimento e a formação interdisciplinar e multidisciplinar do pesquisador. Essa formação abrange as áreas da Sociologia, Ciência Política, Antropologia, Arquitetura, Urbanismo, Geografia, História, Literatura, Artes e Comunicações, Economia, Saúde Pública, Educação e Direito Internacional.

Assim, esses dois objetivos constituem a meta primordial do PROLAM/USP que é produzir o conhecimento integrado dessa porção do continente, com o qual se pretende fortalecer os laços econômicos, políticos, sociais e culturais entre o Brasil, a América Hispânica e o Caribe e promover o desenvolvimento profissional de pessoas formadas em um ambiente multidisciplinar e de integração latino-americana.

O projeto científico do PROLAM/USP estrutura-se a partir do tema Inserção da América Latina nos Processos Históricos Contemporâneos, interpretado a partir de três Linhas de Pesquisa, sendo elas: Comunicação e Cultura; Práticas Políticas e Relações Internacionais e Sociedade, Economia e Estado, descritas abaixo.

- Comunicação e Cultura contempla o estudo da comunicação, da produção artística e da crítica cultural na América Latina. Estuda as teorias e os processos de comunicação, destacando os aspectos políticos, econômicos, sociais e culturais de integração nessa região. Realiza análises comparadas sobre a produção artística e o pensamento crítico da modernidade latinoamericana, com o objetivo de discutir as contribuições da arte e da literatura para a formação da consciência em relação à identidade cultural. 
- Práticas Políticas e Relações Internacionais estuda as práticas das representações políticas, das relações internacionais e comerciais na América Latina. Analisa as ideologias e práticas sócio-políticas que caracterizam a história latino-americana, desde a consolidação dos Estados Nacionais até a atualidade, mediante a análise dos programas liberais, nacionalistas e socialistas norteados pelas perspectivas autoritárias e democráticas. Esta linha de pesquisa objetiva também o estudo teórico-prático do processo de integração econômica da América Latina no que concerne aos problemas ligados aos aspectos políticos e institucionais, especialmente, da Associação Latino-Americana de Livre Comércio (ALALC) e ao Mercado Comum do Sul (MERCOSUL).

- Sociedade, Economia e Estado orienta-se para a análise da formação social da América Latina, tendo em vista o desenvolvimento do capitalismo moderno, e análise de sua transformação em virtude do processo contemporâneo de internacionalização e integração da economia mundial. Focaliza as relações entre as estruturas sócio-demográficas, econômicas e políticas a fim de detectar as transformações e os conflitos sociais contemporâneos, especialmente, nas diferentes dimensões do trabalho e na organização do espaço urbano. Objetiva também, de forma complementar e intrinsecamente associada, o estudo da reestruturação do Estado na região latino-americana e a avaliação dos novos formatos das políticas públicas, nacionais e internacionais, praticadas na região.

O PROLAM/USP registra, ao final do ano de 2001, 31 professores permanentes, 61 (sessenta e um) mestrandos, 25 (vinte e cinco) doutorandos e 118 (cento e dezoito) dissertações defendidas (Gráficos 1 e 2). 


\section{(Gráfico 1)}

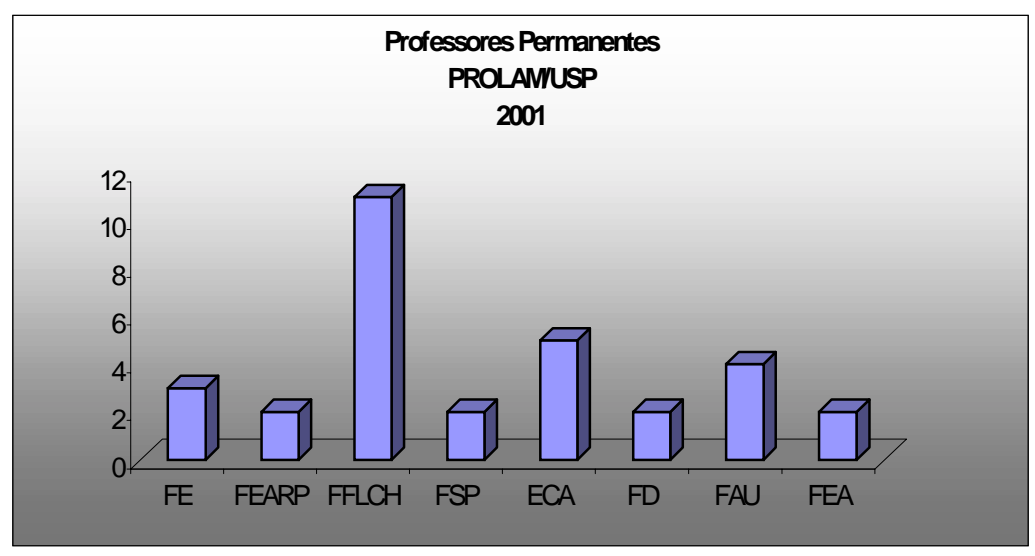

(Gráfico 2)

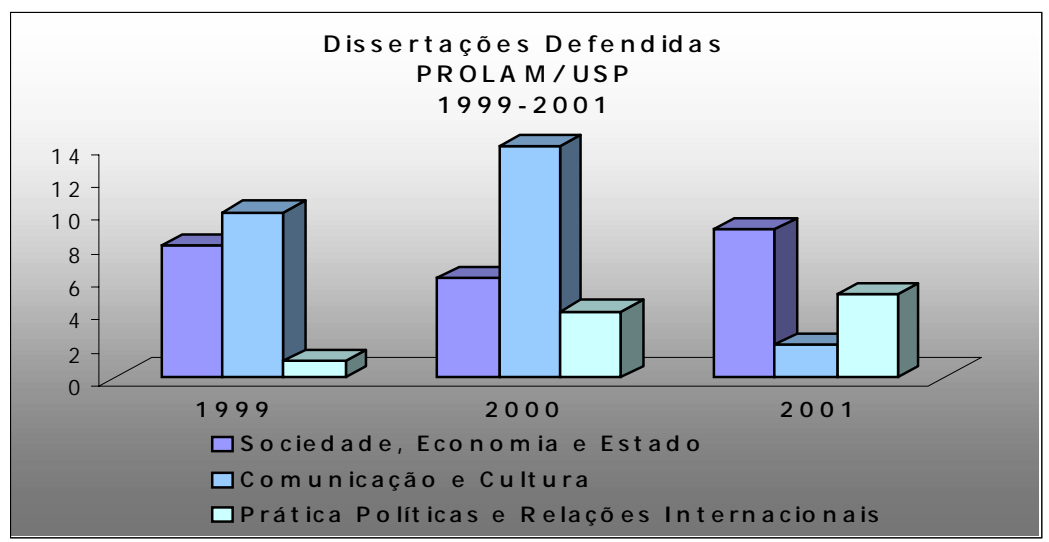

A taxa de desligamento do PROGRAMA é reduzida, mantendo-se relativamente constante ao longo dos últimos anos, e o tempo de titulação vem decrescendo, conforme as diretrizes da Universidade e da Coordenação de Aperfeiçoamento do Ensino Superior (Gráficos 3 e 4).

\section{(Gráfico 3)}

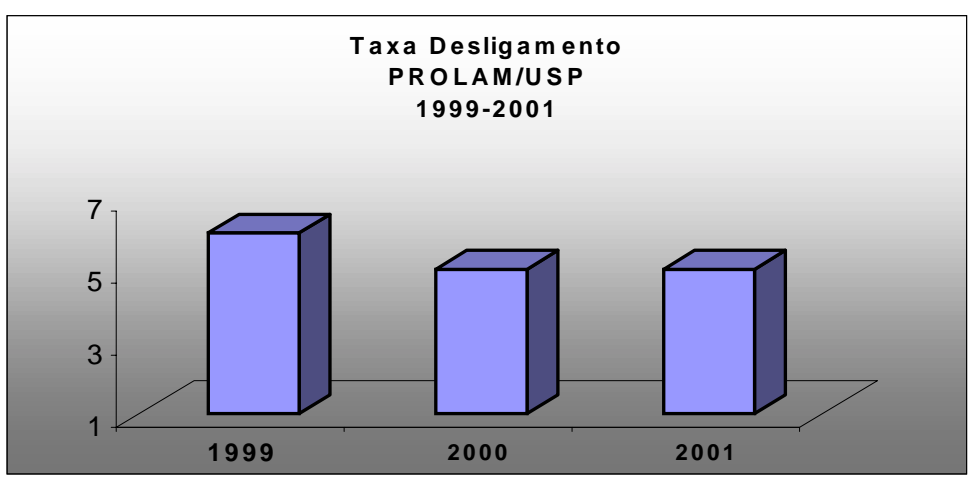


(Gráfico 4)

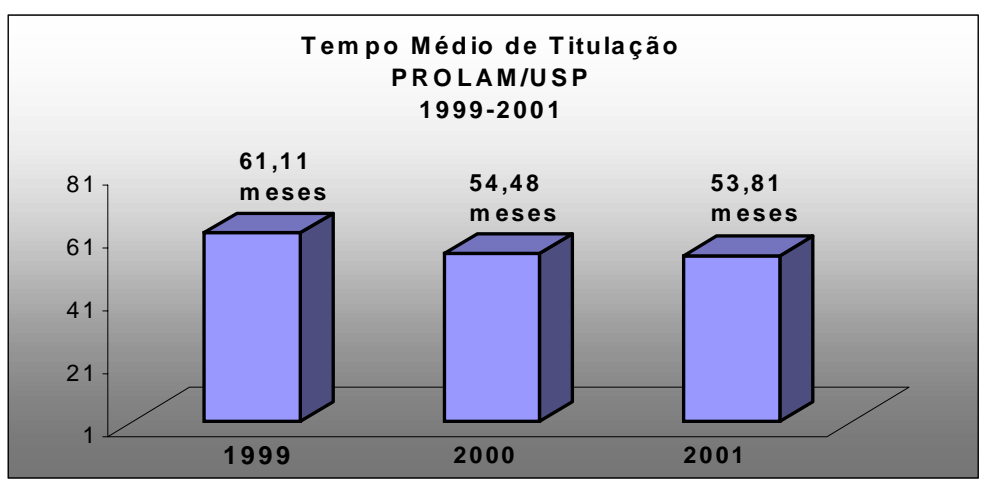

Os cursos de mestrado e doutorado têm como eixo estruturante as disciplinas de Metodologia Científica, e o desenvolvimento das pesquisas que originam as dissertações e teses tem como local de debate e aprofundamento a disciplina Laboratório de Dissertações e Teses. São ministradas de forma regular aproximadamente 9 (nove) disciplinas por semestre, entre as quais destacamos aquelas que foram ministradas nos dois últimos semestres: A Alca, a Integração Global e a "Nova Economia", ministrada pelo Prof. Dr. Gustavo Arce (Prof. Visitante da Universidad de La República - Uruguai ); Análise das Relações Internacionais (FLS - 5893), ministrada pelo Prof. Dr. Leonel Itaussu de Almeida Melo; Arte Contemporânea na América Latina (IAL - 5736), ministrada pela Profa. Dra. Profa. Dra. Lisbeth Rebollo Gonçalves; Avaliação Educacional: Pressupostos TeóricoMetodológicos e Propostas em Realização no Brasil (EDA - 5007), ministrada pela Profa. Dra. Sandra Maria Zákia Lian Sousa; Campo Universitário e Cultura no Brasil anos 30, 40 e 50 (EDA - 5727), ministrada pelo Prof. Dr. Afrânio Mendes Catani; Economia do Território (IAL 5758), ministrada pelo Prof. Dr. Christian Azaïs (Prof. Visitante da Université de Picardie Jules Verne - França); Economia do Trabalho II - O Mercado de Trabalho Contemporâneo - Foco na América Latina (EAE - 5861), ministrada pela Profa. Dra. Maria Cristina Cacciamali; Economia Política Internacional (IAL - 5747), ministrada pelo Prof. Dr. Amaury Patrick Gremaud; Integração Econômica Regional (IAL - 5746), ministrada pelo Prof. Dr. Márcio Bobik Braga; Estrutura e Dinâmica da Economia Mundial Contemporânea (FLH - 5069), ministrada pelo Prof. Dr. Osvaldo Luis Angel Coggiola; Fundamentos Metodológicos do Conhecimento Científico (IAL - 5738), ministrada pela 
Profa. Dra. Cremilda Celeste de Araújo Medina; Laboratório de Dissertações e Teses Metodologia do Trabalho Científico (IAL - 5752), ministrada pela Profa. Dra. Maria Cristina Cacciamali; Métodos e Técnicas de Avaliação da Estruturação do Espaço Nacional (AUT - 5810), ministrada pela Profa. Dra. Sueli Ramos Schiffer e Prof. Dr. Csaba Deák; Organizações Internacionais de Integração Econômica na América Latina, África e Ásia (DIN - 5706), ministrada pela Profa. Dra. Araminta de Azevedo Mercadante; Políticas Urbanas no Brasil (AUP - 5839), ministrada pela Profa. Dra. Maria Lucia Refinetti Martins; Posição dos Estados Unidos nas Relações Interamericanas (IAL - 5728), ministrada pela Profa. Dra. Antonia Fernanda Pacca de Almeida Wright; Teoria Geral do Direito da Integração (DIN - 5857), ministrada pelo Profs. Drs. Paulo Borba Casella; e Teorias da Urbanização (AUH - 5701), ministrada pela Profa. Dra. Rebeca Scherer.

\section{Contribuição acadêmica}

Os 31 (trinta e um) Professores Doutores Orientadores do PROLAM/USP tornam concretas as linhas de pesquisa do Programa - Comunicação e Cultura; Práticas Políticas e Relações Internacionais; e Sociedade, Economia e Estado - desenvolvendo projetos de pesquisas e orientando dissertações e teses sobre temas vinculados. Assim, nesta seção apresentaremos inicialmente, sem exaurir todas as atividades de pesquisa em andamento no PROGRAMA, 7 (sete) projetos de pesquisa em andamento, selecionados pelo seu caráter de longo prazo no âmbito das atividades do PROLAM/USP. Na sequiência, comentaremos os campos de atuação das dissertações defendidas tendo como objeto de estudo a integração no MERCOSUL:

\subsection{Mundialização, regulação social e padrão contemporâneo de desenvolvimento no Brasil sob a perspectiva da integração regional. Paralelos com Argentina e México.}

Este projeto de pesquisa, coordenado pelos Professores Doutores Maria Cristina Cacciamali (FEA/PROLAM/USP) e Jaime Marques-Pereira (IHEAL - Sorbonne e Université Lille 1), vem sendo desenvolvido desde o final de 1997 e seu formato atual prevê atividades até o ano de 2003. Envolve 10 (dez) professores: 4 (quatro) do 
PROLAM/USP, 4 (quatro) de universidades francesas, 1 (um) pesquisador argentino e 1 (um) mexicano. Esta parceria vem contribuindo para ampliar e aprofundar o conhecimento sobre o padrão de desenvolvimento contemporâneo, seus efeitos sobre a América Latina, os processos de integração, de liberalização comercial e a política social, especialmente no campo do mercado de trabalho. Foram produzidos artigos científicos, publicados no Brasil e no exterior, individuais e coletivos e realizadas oficinas de trabalho.

\subsection{Plural}

Este projeto de pesquisa, coordenado pela Profa. Dra. Cremilda Celeste de Araújo Medina (ECA/PROLAM/USP), enfoca a crise de paradigmas científicos e sua efetividade para responder a temas inseridos na problemática contemporânea latino-americana. Envolve, em consonância com determinados temas selecionados, parte expressiva do corpo

docente dos cursos de Mestrado e Doutorado. Os resultados são difundidos por meio de livros coletivos e artigos publicados em revistas científicas ou especializadas. Foram produzidos: seminários interdisciplinares; programas de comunicação social; publicação de um periódico anual da série Novo Pacto para Ciência, dissertações e teses na perspectiva interdisciplinar. Tem como foco privilegiado de análise a área de Comunicação. Foram produzidos artigos científicos, publicados no Brasil e no exterior, individuais e coletivos e realizadas oficinas de trabalho.

\subsection{Produção Artística e Crítica Cultural na América}

Este projeto é coordenado pela Profa. Dra. Lisbeth Rebollo Gonçalves (ECA/PROLAM/USP) com a participação dos Professores Doutores Irlemar Chiampi (FFLCH/PROLAM/USP), Dilma de Meio Silva (ECA/PROLAM/USP) e Kazadi Wa Mukuna (Kent University) desenvolve estudos comparados sobre a produção artística e o pensamento crítico da modernidade latino-americana. Um segmento do projeto abarca a importância e influência da presença africana na região na música e nas artes plásticas. Os resultados são divulgados por meio de exposições, vídeos e outras mídias, além de artigos em periódicos especializados. 


\subsection{Relações Internacionais}

Este projeto coordenado pelo Prof. Dr. Paulo Borba Casella (FD/PROLAM/USP), compreende projetos desenvolvidos pelos Professores Doutores José Augusto Guilhon de Albuquerque (FFLCH/PROLAM/USP), Amaury Patrick Gremaud (FEARP/PROLAM/USP), Márcio Bobik Braga (FEARP/PROLAM/USP), e Elizabeth Balbachevsky (FFLCH/PROLAM/USP) focando os processos de integração econômica da América Latina, os impactos da política mundial sobre esta região no que concerne as relações econômicas, políticas e institucionais no MERCOSUL, ALALC, ALADI, Pacto Andino, Bacia do Prata e Pacto Amazônico. Envolve regularmente professores de outras universidades latino-americanas. Nos quatro últimos anos, contou com a participação dos Professores Doutores Raúl Bernal-Meza (Universidad del Centro de la Provincia de Buenos Aires - Argentina), Carlos Antonio Romero Méndez (Universidad Central de Venezuela Venezuela), Gustavo Alberto Arce Rivera (Universidad de La República - Uruguai) e Catalina Banko (Universidad Central de Venezuela - Venezuela) a partir de 2002. Os resultados são difundidos principalmente por meio de artigos publicados em revistas científicas e livros.

\subsection{Urbanização, Metropolização, Emprego e Gestão Urbana na América Latina}

Este projeto de pesquisa, coordenado pela Profa. Dra. Maria Lúcia Refinetti Martins (FAU/PROLAM/USP), com a participação das Professoras Doutoras Amália Inês Geraiges de Lemos (FFLCH/PROLAM/USP), Sueli Ramos Schiffer (FAU/PROLAM/USP) e Rebeca Scherer (FAU/PROLAM/USP) enfoca as transformações estruturais bem como as mudanças das funções das metrópoles latino - americanas e os distintos impactos da mundialização sobre elas. A pesquisa busca descrever e avaliar as formas como urbanismo, políticas urbanas e práticas urbanísticas têm interferido na alocação de vantagens e distribuição do produto social promovendo ou dificultando processos de inclusão. Os resultados são difundidos principalmente por meio de artigos publicados em livros e revistas científicas. 


\subsection{América Latina frente aos Capitalismos Mundiais}

Este projeto de pesquisa, coordenado pelo Prof. Dr. Sedi Hirano (FFLCH/PROLAM/USP), com a colaboração dos Professores Doutores Leonel Itaussu de Almeida Mello (FFLCH/PROLAM/USP) e Osvaldo Luis Angel Coggiola (FFLCH/PROLAM/USP), insere-se no projeto de pesquisa Relações e Práticas Políticas na América Latina. Objetiva analisar as especificidades da inserção da sociedade latinoamericana frente ao desenvolvimento do capitalismo contemporâneo. Os resultados são difundidos principalmente por meio de artigos publicados em livros e revistas científicas.

\subsection{Políticas Públicas no Campo do Trabalho, Educação e Saúde}

Este projeto de pesquisa coordenado pela Profa. Dra. Lúcia Emilia Nuevo Barreto Bruno (FE/PROLAM/USP), com a participação dos Professores Doutores Afrânio Mendes Catani (FE/PROLAM/USP), Maria Cristina Cacciamali (FEA/PROLAM/USP), Sandra Maria Zákia Lian Sousa (FE/PROLAM/USP) e Sueli Gandolfi Dallari (FSP/PROLAM/USP), objetiva avaliar a mudança de concepção da política pública, novas regulamentações e a implementação de programas e suas conseqüências na América Latina no campo do trabalho, educação e saúde. Os resultados são difundidos através de publicação de artigos, individuais e coletivos, em revistas científicas e em livros.

\section{Seminários Internacionais do Grupo de Trabalho MERCOSUL}

O Grupo de Trabalho Mercosul foi criado pela Reitoria da Universidade de São Paulo em 01 de maio de 1999 com o objetivo de suscitar temas, posteriormente debatê-los e sistematizar as conclusões sobre questões emergentes do processo de integração regional. A metodologia empregada para alcançar os objetivos foi a realização de seminários, reunindo especialistas do Brasil e do exterior. O Programa de Pós-Graduação em Integração da América Latina - PROLAM/USP, a Comissão de Cooperação Internacional - CCInt/USP e o Programa de Lideranças para o Desenvolvimento Sustentável no Mercosul - PROLIDES concretizaram, entre 2000 e 2001, 3 seminários internacionais sobre os seguintes temas: "Mercosul, Presente e Futuro" - realizado em maio de 2000, "Trabalho e emprego no 
Mercosul" - realizado em maio de 2001; e "Direitos Humanos no Mercosul" - realizado em dezembro de 2001. Adicionalmente, ao longo dos últimos 3 anos, o PROGRAMA organizou 20 seminários e recebeu a visita de 34 professores visitantes (Gráfico 5 e 6 ).

(Gráfico 5)

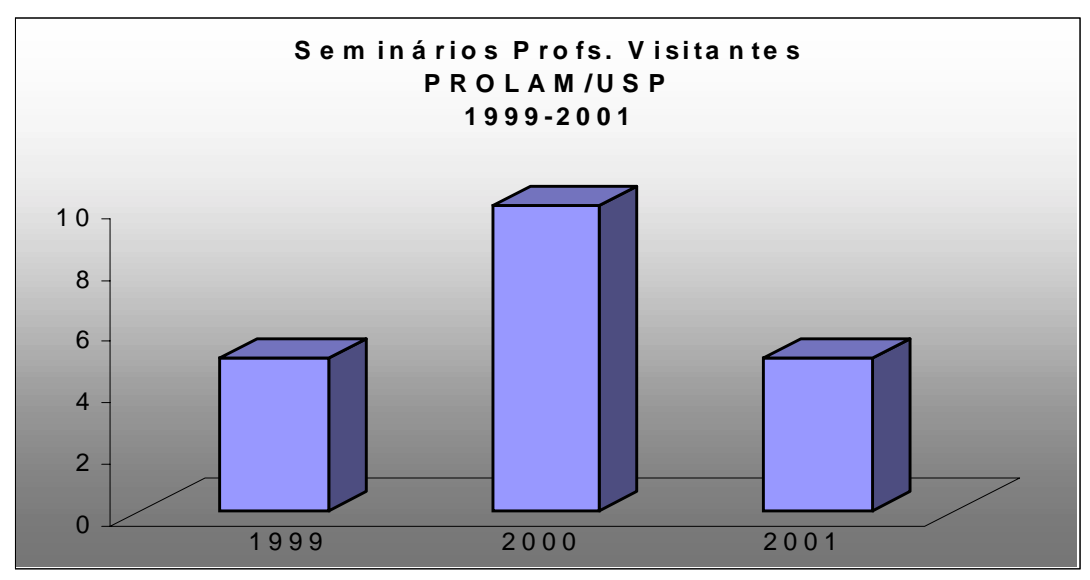

\section{(Gráfico 6)}

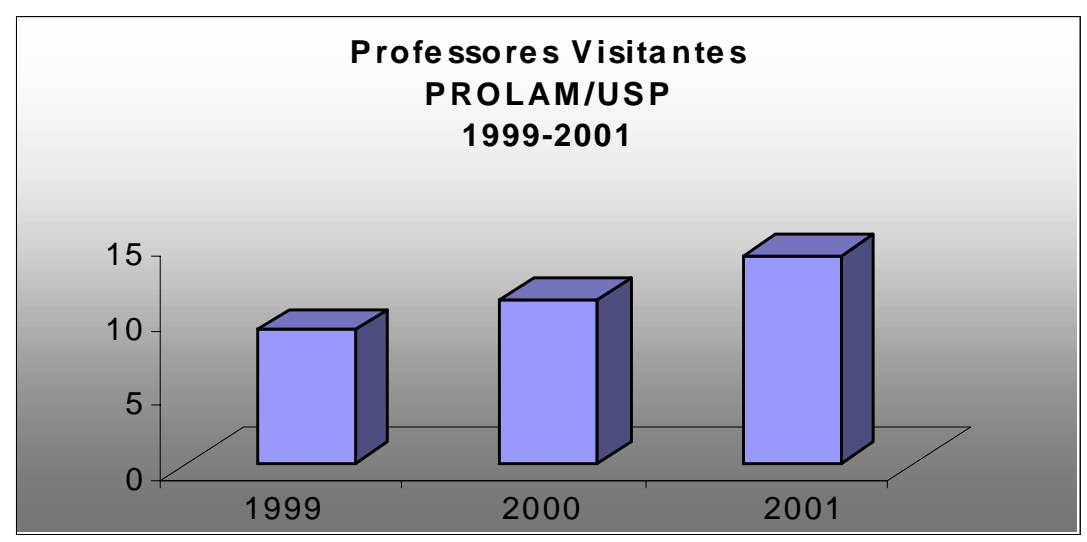

\section{Mercosul: tema primordial dentre as dissertações defendidas}

Dentre as dissertações defendidas até o final de 2001, 64 focam a integração a partir do MERCOSUL - compreendendo os países Argentina, Bolívia, Brasil, Chile, Paraguai e Uruguai. Inserem-se nas três linhas de pesquisa do PROLAM/USP e contribuem com 
trabalhos originais e sistematizados sobre temas, questões e objetos de estudos pouco pesquisados e relevantes para o entendimento da região e a construção da integração.

Dessa maneira, no âmbito da Linha de Pesquisa Comunicação e Cultura, a modernidade é discutida e analisada a partir das artes plásticas e do cinema; a música da fronteira é estudada como expressão cultural e de integração entre os povos da região; e o papel da mídia é analisado a partir de diferentes óticas, desde a cobertura jornalística, suas relações mercantis e com o poder político e econômico, bem como sua importância para a construção da democracia e da vida política dos países da região.

As relações internacionais no MERCOSUL são analisadas sob diferentes enfoques e temas. Uma linha de estudos expõe as contradições de construir a integração econômica numa região aonde os Poderes Executivos predominam sobre as outras duas esferas de poder. Analisam-se temas como a economia e a política da integração regional; federalismo; política nuclear; ampliação e reorganização das relações comerciais; reestruturação produtiva; reestruturação bancária e o setor financeiro; e a reestruturação tributária. Um outro enfoque refere-se à aplicação das leis no MERCOSUL nas relações comerciais, na utilização das práticas de arbitragem e no direito ao consumidor.

As estratégias empresariais no MERCOSUL e suas relações capital trabalho constituem um dos principais campos da Linha de Pesquisa Sociedade, Economia e Estado, enfocando especialmente o papel das organizações representativas dos empresários, os sindicatos, as reformas laborais e as possibilidades para as pequenas e médias empresas urbanas e rurais. Esta linha também é representada por estudos sobre a questão territorial e a problemática nas regiões metropolitanas, especialmente, Buenos Aires e São Paulo. As políticas públicas constituem outro campo de estudo importante destacando-se análises sobre políticas implementadas na área social de habitação, trabalho e saúde na direção de maior acesso e ampliação da cidadania. As reformas educacionais que estão sendo efetivadas no ensino médio e ensino superior também foram alvo de estudo, bem como as experiências realizadas na área de educação ambiental. 
Um tema destaque, estudado ao longo destes anos refere-se às ditaduras políticas na região, a ação de sua polícia política, o papel da imprensa e aos modos e à organização da resistência civil no período. Um dos instrumentos para garantir que estes períodos não se repitam pode ser encontrado nos estudos sobre a democracia e os direitos humanos, e sua difusão na ordem internacional.

\section{Mecanismos de retro-alimentação: a auto avaliação}

O PROLAM/USP vem a cada ano aprimorando suas atividades buscando superar lacunas apontadas pela própria comunidade, pela comunidade externa e pelo Comitê da Avaliação da Coordenação de Aperfeiçoamento do Ensino Superior (CAPES). Assim, a Comissão de Pós-Graduação deste Programa definiu a avaliação como um processo

permanente, desenvolvendo uma cultura onde a avaliação é um espaço de reflexão e mudança das ações institucionais, resultando em um instrumento de formação, informação, planejamento e gestão. Dessa maneira, foram estabelecidos os seguintes objetos específicos para o processo de avaliação permanente:

1. relações e fluxos de informação entre as práticas cotidianas do curso;

2. projeto didático científico;

3. atividades de extensão;

4. política acadêmica da Universidade de São Paulo e do Ministério da Educação;

5. política acadêmica do PROLAM/USP e da USP; e

6. relação entre as práticas administrativas do PROLAM/USP e da USP.

Ao final de 2001 implementou-se a Sondagem denominada Perspectivas 2001 Propostas da Comunidade, que teve como objetivo levantar informações sobre a adequação das atividades desenvolvidas no Programa, sistematizar as sugestões da comunidade e operacionalizá-las à Comissão de Pós-Graduação para que as mesmas tornem-se metas norteadoras de suas ações. Dentre as sugestões apontadas pela comunidade destacam-se: 
- ampliação de quadro de professores;

- ampliação do leque de disciplinas, por linha de pesquisa, especialmente na área de relações internacionais, economia e comunicação;

- manutenção da visão multidisciplinar;

- aperfeiçoamento acadêmico e administrativo;

- aprofundar o intercâmbio com outros países;

- conquistar maior espaço físico;

- maior engajamento de professores e alunos na formação de grupos de pesquisa;

- melhora na relação orientando/orientador.

De acordo com o conteúdo das respostas fornecidas pelos participantes da Sondagem, a Comissão de Pós-Graduação do PROLAM/USP definiu metas e implementou medidas, renovando o quadro de funcionário, instalando novos procedimentos de comunicação e atendimento aos alunos, professores e visitantes, reorientou disciplinas e estabeleceu disciplinas básicas, definiu seminários multidisciplinares focados em cada linha e projeto de pesquisa, transformou a home page em um instrumento vivo de comunicação acadêmico e científico; e criou um espaço para divulgação de ensaios e artigos científicos com conselho editorial de arbitragem composto por pesquisadores de universidades brasileiras e do exterior devidamente indexado, denominado Cadernos PROLAM/USP.

\section{Considerações finais}

A integração econômica constitui um processo lento a ser construído pelos atores sociais, suas demandas políticas e a criação de instituições. A UNIVERSIDADE tem um papel especial e relevante nesse processo. Produzir conhecimentos orientados para aprimorar a interatividade da população latino-americana, destruir fantasias preconceituosas entre os povos e grupos sociais, e preparar pessoas com elevado conhecimento científico e sólida formação humanista para interagir nesse processo compõem as funções primordiais da UNIVERSIDADE no presente momento. 
O Programa de Pós-Graduação em Integração da América Latina (PROLAM/USP), comprometido com esses princípios, tem demonstrado vitalidade e se constitui num pólo agregador dos estudiosos sobre a temática latino-americana sob a ótica da Integração. A escolha do tema por parte do quadro de Professores Orientadores, sua dedicação ao Programa além de sua Unidade de origem, o empenho dos alunos e seu processo de

avaliação permanente torna-o peculiar e bem sucedido. $\mathrm{O}$ estudo comparativo e a multidisciplinaridade, por sua vez, criam um ambiente de pesquisa inovador e de profícuo debate.

O intercâmbio crescente com pesquisadores brasileiros e de outros países, o número e a qualidade de seminários internacionais e o reconhecimento do PROLAM/USP nos meios acadêmicos-científicos revelam a excelência de sua produção e a relevância dos estudos efetuados e que vêm sendo realizados. Dessa maneira, PROLAM/USP contribui e compõe as funções políticas e sociais que devem ser exercidas pela Universidade neste momento de integração mundial.

\section{Bibliografia}

BARDIN, L. Análise de Conteúdo. Lisboa: Edições 70, 2000, 223 p.

CACCIAMALI, M. C. Para Além dos Dez Primeiros Anos - 1989-1999 - Um Olhar sobre o PROLAM/USP. São Paulo: PROLAM/USP, 2000, 94 p.

CACCIAMALI, M. C. 12 Anos Pesquisando a América Latina - 1989-2001 - Trajetórias e Perspectivas. São Paulo: PROLAM/USP, 2001, 111 p.

VIERA, L. Cidadania e Globalização. Rio de Janeiro: Record, 2a edição, 1997, 137 p.

WARREN-SCHERER, I. Cidadania sem Fronteiras. Ações Coletivas na Globalização. São Paulo: Hucitec, 1999, 95p.

WEBER, M. O Político e o Cientista, Lisboa: Editorial Presença, 1979, 151 p. 
